


\section{Os desafios da}

\section{comunicação na era da} conectividade: Entrevista com Federico Casalegno

\section{The challenges of communication in the age of conectivity: Interview with Federico Casalegno}

\section{Aline Bianchini' ๘ Erika Oikawa}

\section{Ciro Götz ${ }^{3}$}

\section{ENTREVISTA}

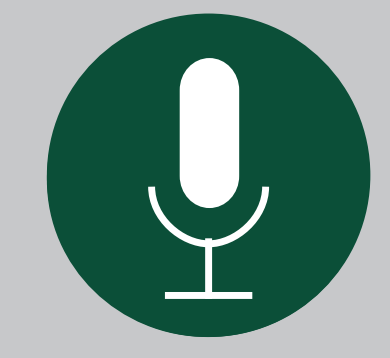

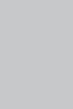

Diretor do Mobile Experience Lab, do Massachusetts Institute of Technology (MIT), Federico Casalegno lidera projetos que envolvem a interação e conexão entre pessoas, informações e espaço físico. É doutor em Sociologia da Cultura e Comunicação pela Université René Descartes/Paris V, Sorbonne, e foi premiado por várias instituições e universidades, como a Glasgow School of Art, da University of Glasgow, e a Jiangnan University School of Design, de Wuxi, na China.

Casalegno concedeu entrevista à Sessões do Imaginário durante o Seminário Cooperação e Internacionalização em Comunicação, realizado em setembro de 2014, em comemoração aos 20 anos do Programa de Pós-Graduação em Comunicação Social (PPGCOM) da PUCRS. Em sua conferência, o pesquisador do MIT destacou diversos projetos desenvolvidos por seu laboratório, inclusive o Locast Civic Media, que contou com a participação de alunos da Famecos em 2010.

Outra iniciativa destacada pelo pesquisador foi o Youth Mapping, projeto desenvolvido em parceria com a Unicef nas favelas do Rio de Janeiro. Por meio de oficinas e disponibilização de internet e smartphones, jovens das comunidades carentes cariocas foram incentivados a registrarem potenciais riscos ambientais em seus bairros e vizinhanças. O mapeamento coletivo, com informações geolocalizadas acerca de locais de difícil acesso, serviu de base para que as comunidades pudessem exigir melhorias do poder público local, além de incentivar a participação e o engajamento social desses jovens.

Diante das experiências desenvolvidas pelo Mobile Experience Lab, o pesquisador afirma que, mais do que aumentar as inúmeras conexões e interações no mundo contemporâneo, é preciso torná-las efetivas na comunicação entre os seres humanos. 
Sessões do Imaginário - Como você avalia as reapropriações que as comunidades envolvidas no projeto Youth Mapping (Mapeamento da Juventude) fizeram dos espaços públicos, do meio ambiente local, e qual a importância dessa forma de engajamento e de comunicação entre comunidades e governo?

Federico Casalegno - A reapropriação do espaço por meio das novas mídias - seja tirando fotos, fazendo vídeos, escrevendo histórias sobre os meio ambientes locais - representa a emergência de novas formas de narrativas, então, vejo vários elementos importantes nesse contexto. Primeiro, essas comunidades se apropriam desses espaços narrando histórias; segundo, elas publicam essas histórias, ou seja, fazem essas narrativas se tornarem visíveis; e, terceiro, permitem que o conteúdo das favelas realmente chegue até os líderes políticos. Por fim, também como um elemento muito importante, é que essa comunicação não ocorre somente de cima para baixo, mas de forma horizontal. Ou seja, as comunidades locais começam a falar umas com as outras e isso é muito interessante porque é uma maneira de cristalizar novas formas de comunicação e de relações sociais.

SI - E você acha que esse poderia ser um modelo que os governantes poderiam adotar?

FC - Com certeza. Os governos começam a prestar realmente atenção no crowdsourcing e estão cada vez mais interessados em entender como podem utilizar o poder das massas e se apropriar do conhecimento gerado no coletivo. Isso agora é visível e uma forma nova dos governos estabelecerem um contato mais próximo com os cidadãos.

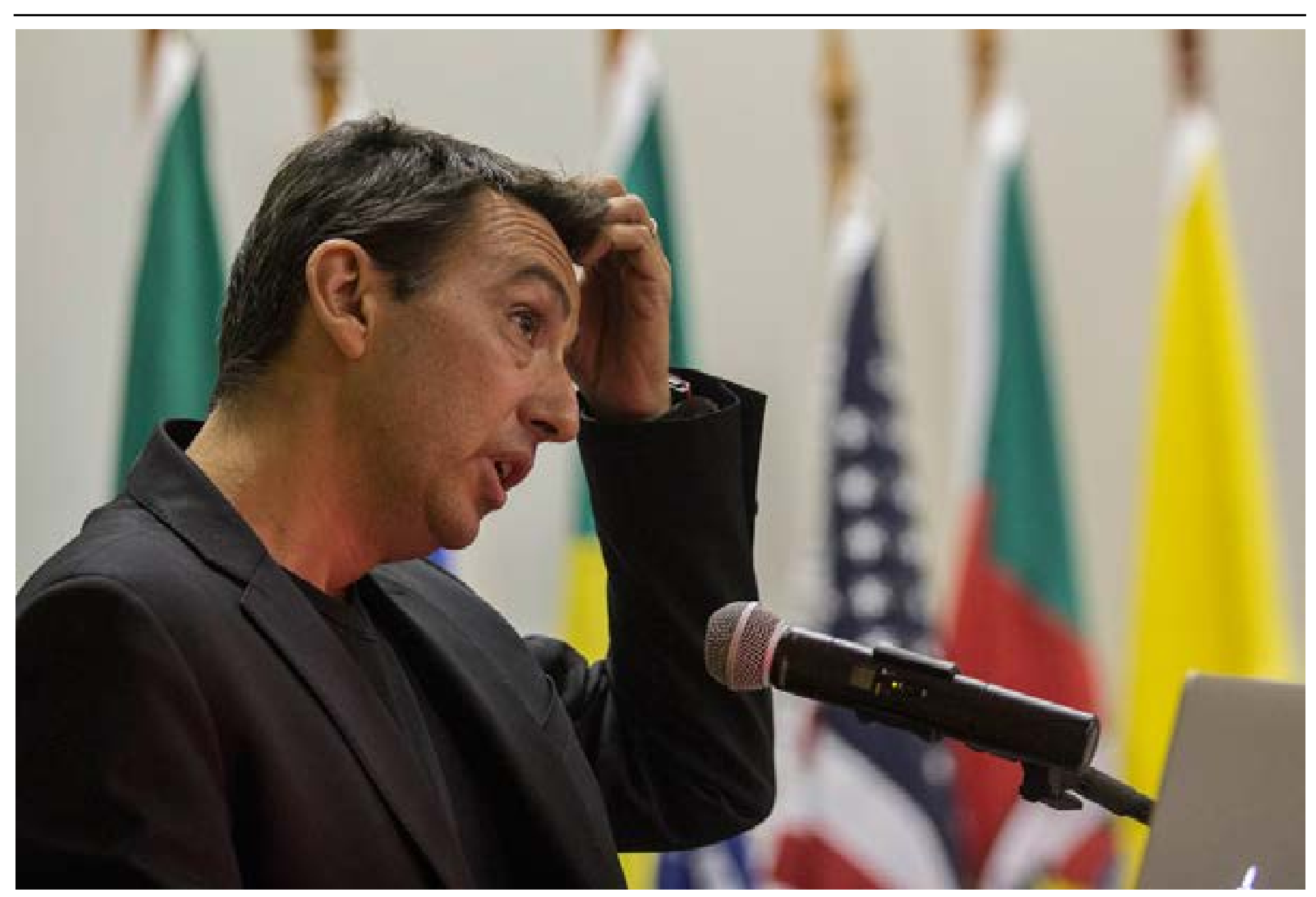

111 PORTO ALEGRE | v. 19| n. 31 | 2014 | pp. 110-113 Sessões do Imaginário 
SI - Em sua conferência, no Seminário comemorativo de 20 anos do PPGCOM/PUCRS, você também falou sobre a aproximação e até mesmo a inserção de tecnologias no corpo humano. Como a memória humana pode estar sendo afetada por esse processo?

FC - Há 20 anos, todo mundo sabia pelo menos dez números de telefone de cor. Hoje, ninguém memoriza ou, às vezes, não sabe o seu próprio telefone ou o dos seus pais. Nós dependemos cada vez mais da tecnologia. Não apenas para memorizar números de telefone, mas para todas as atividades cotidianas. Se você vai a um aeroporto, por exemplo, usa o celular para fazer seu check-in. Toda a nossa informação está armazenada em nossos dispositivos. A questão é como nossa memória é afetada por isso. Platão, quando inventaram o livro, também preocupou-se com a perda da memória do homem, pois, a partir daí, todas as informações estariam armazenadas nos livros. Então, essa tem sido uma preocupação constante. Porém hoje, há uma aceleração: temos mais tecnologias e há mais complexidade em manejar a informação. Assim, a complexidade é muito maior.

SI - Você falou também sobre o conceito de hands on. $\mathrm{O}$ que ele significa no contexto das pesquisas do Media Lab?

FC - Muitos dos nossos trabalhos e pesquisas se dão pelo processo de "aprender fazendo", tentando fazer coisas. Isso é possível em função das novas mídias e novas formas de comunicação. Hoje, por exemplo, é muito mais fácil fazer protótipos do que há cinco ou dez anos. A ideia é "aprender fazendo", criando artefatos. Um dos maiores promotores dessa ideia é Seymour Papert. Através de Jean Piaget, Papert trabalha a teoria do active learning e a do Construtivismo, com a ideia de que, para que você seja capaz de aprender precisa estar ativamente envolvido e procurando pela informação correta, construindo seu próprio processo de aprendizado. $O$ que Papert adicionou foi a ideia do Construcionismo: então, você não só precisa usar seu conhecimento intelectual, como também precisa fazer protótipos de seus artefatos, precisa experimentar seu conhecimento. Assim, o conhecimento e aprendizado acontecem quando você cria um artefato e coloca esse objeto no mundo real, testando, redesenhando e aperfeiçoando-o. Por tentativa e erro. No Media Lab, nossos projetos têm muitos protótipos - eles não são produtos, apenas nos ajudam a aprender e experimentar coisas.

SI - Você disse que há uma grande ênfase hoje em dia na busca pela conectividade, mas que deveríamos atentar mais para a comunicação e para como as pessoas se apropriam das mídias, das tecnologias. Como você vê, hoje, essa relação entre conectividade e comunicação?

FC - Sim, há um grande impulso para a conexão, o que é algo fantástico. Não se trata aqui de ser contra essa crescente conectividade ou de fazer afirmações contra a tecnologia ou ao seu desenvolvimento. No caso da Internet das Coisas (Internet of Things), no qual cada objeto está conectado a uma rede, conectado a outro objeto, isso aumenta a conectividade, mas não significa que esteja aumentando ou melhorando a comunicação humana. Então, cabe a nós a questão da educação, de saber lidar com toda essa conectividade. Nós não temos comportamentos sociais (social behaviors) sobre a forma de utilizar os telefones celulares em locais públicos ou durante as conversas

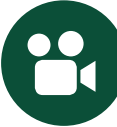

ASSISTA AO VÍDEO

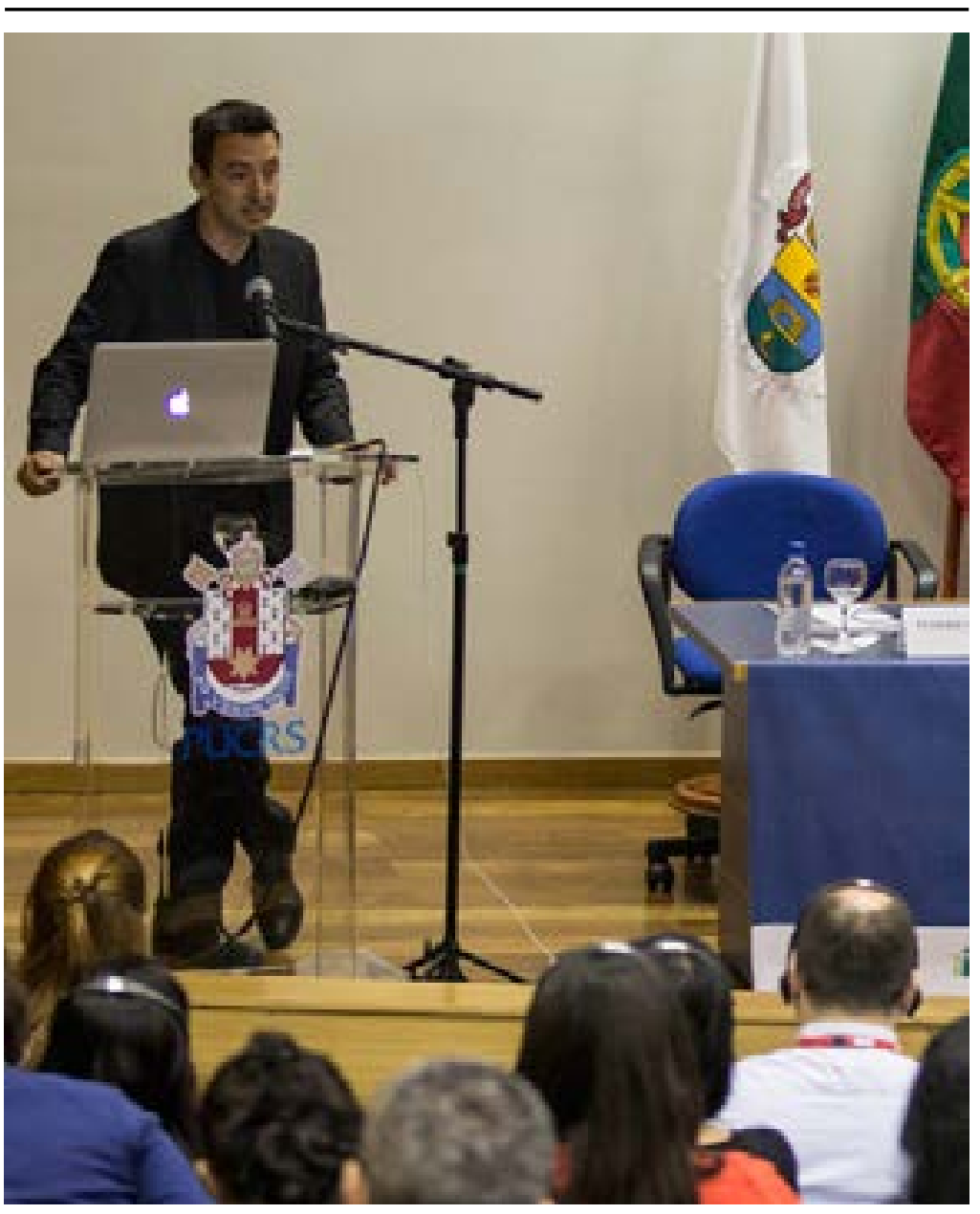

face a face, e não sabemos como conduzir todas essas situações. Estamos, realmente, redescobrindo os objetos e isso vai ser cada vez mais crescente. Hoje, temos telefones celulares e começamos a ter objetos vestíveis (wearable objects), desde pulseiras a roupas, camisetas e calças providas de computação. Mas, como transformar essa conectividade crescente em formas de comunicação que realmente criem conexões entre os seres humanos? Este é o verdadeiro desafio. 


\section{Notas}

1. Doutoranda do Programa de Pós-Graduação em Comunicação Social da Pontifícia Universidade Católica do Rio Grande do Sul (PPGCOM/PUCRS Av. Ipiranga, 6681 - Prédio 7, Sala 319, CEP: 90619900, Porto Alegre - RS, Brasil). Bolsista CAPES. E-mail: li.bianchini@gmail.com

2. Doutoranda do Programa de Pós-Graduação em Comunicação Social da Pontifícia Universidade Católica do Rio Grande do Sul (PPGCOM/PUCRS - Av. Ipiranga, 6681 - Prédio 7, Sala 319, CEP: 90619-900, Porto Alegre - RS, Brasil). Bolsista CAPES/FAPERGS. E-mail: erikaoikawa@gmail.com

3. Mestrando do Programa de Pós-Graduação em Comunicação Social da Pontifícia Universidade Católica do Rio Grande do Sul (PPGCOM/PUCRS - Av. Ipiranga, 6681 - Prédio 7, Sala 319, CEP: 90619-900, Porto Alegre - RS, Brasil). Bolsista FAPERGS. E-mail: cirogotz@gmail.com 